\title{
Dietary quercetin ameliorates TPT-induced hepatic oxidative damage and apoptosis in zebrafish
}

Chunnuan Zhang ( $\nabla$ zhangchunnuan@haust.edu.cn )

Henan University of Science and Technology

Yuheng Wang

Jiangsu Polytechnic College of Agriculture and Forestry

Hongtao Ren

Henan University of Science and Technology

Junhui Wang

Henan University of Science and Technology

Dongxue Jiang

Henan University of Science and Technology

Xiaoyu Yuan

Henan University of Science and Technology

\section{Research Article}

Keywords: Triphenyltin, Quercetin, Oxidative stress, Inflammation, Apoptosis

Posted Date: March 30th, 2021

DOI: https://doi.org/10.21203/rs.3.rs-339016/v1

License: (c) (i) This work is licensed under a Creative Commons Attribution 4.0 International License.

Read Full License 


\section{Abstract}

The objective of this study was to determine the effects of quercetin on oxidative stress and apoptosis induced by TPT in zebrafish. 240 fish were divided into 4 groups with three repeats. D1: fish fed with the basal diet as the control group. D2: fish fed with basal diet and exposed in $10 \mathrm{ng} / \mathrm{L}$ TPT. D3: fish fed diets containing $100 \mathrm{mg} / \mathrm{Kg}$ quercetin and exposed in 10ng/L TPT. D4: fish fed diets containing $100 \mathrm{mg} / \mathrm{Kg}$ quercetin. The results showed that quercetin could ameliorate oxidative stress, which decreased MDA, NO levels and improved antioxidant enzyme activities. The key apoptotic gene expressions, including caspase3, Bax and caspase 9 mRNA expression were significantly induced by TPT exposure as compared with the control group, while notably decreased the Bcl-2 gene. However, dietary quercetin prevented a significant increase in Bax, caspase 3 and caspase9 mRNA levels induced by TPT exposure, but increased $\mathrm{Bcl}-2 \mathrm{mRNA}$ levels. The results of our study also demonstrated that $10 \mathrm{ng} / \mathrm{L}$ TPT significantly upregulated TNF-a, IL-1 $\beta$, IL-8, and NF-kB p65 gene expression and down-regulated IL-10 and IkB expression compared to the control group. However, TPT-induced inflammation was significantly mitigated in the quercetin treatment group. In conclusion, our findings suggested that quercetin might alleviate hepatic oxidative damage and apoptosis induced by TPT.

\section{Introduction}

Triphenyltin (TPT), an organotin compound, is widely used in agriculture and industry (Hoch 2001). Although the use of TPT has been banned in many countries, there are still some reports of TPT contamination in coastal areas of China (Gao et al. 2017). It has reported that the seafood (fish, sea vegetables, shellfish) contained TPT levels are higher than the TBT levels (Lee et al. 2016). There has been a lot of concern about toxicological and eco-toxicological properties of organotin compounds (Clasen et al. 2017; Chen et al. 2019). An eco-toxicological evaluation of TPT has indicated that aquatic animals might face serious risks with long-term exposure to TPT (Wen et al. 2018). The aquatic products have posed the most exposure risk to humans. Thus, exploring the mechanism of TPT and protective measures is of great importance. In the present study, TPT was used to induce oxidative stress, and evaluated the antioxidant effect of quercetin. This information will be with great interest to explain a well understanding of the toxicology of TPT and the functional effects of quercetin.

Oxidative stress is due to the excessive production of free radicals and the decrease of the activity of the antioxidant defense system, which interferes the equilibrium state of the pro-oxidation system and the antioxidant system (Kennedy et al. 2005). The antioxidants play a pretty crucial role in the health of fish. Excess reactive oxygen species (ROS) are toxic because they can attack and destroy a variety of biological molecules, such as DNA, carbohydrates, proteins and membrane lipids, leading to cell death and tissue damage. ROS is often used as a biomarker of oxidative stress, and its excessive production can induce oxidative damage and apoptosis (Patten et al. 2010). The influence of ROS on the health of fish has become of increasing interest. Many studies have shown that TPT can induce oxidative stress in different aquatic organisms, such as copepods (Tigriopus japonicus) (Yi et al. 2014), green microalgae (Scenedesmus quadricauda) (Xu et al. 2011), rotifers (Brachionus koreanus) (Yi et al. 2016), male 
guppies (Poecilia reticulata) (Zhang et al. 2019) and abalones (Haliotis diversicolor) (Lu et al. 2016). TPT was found to inhibit the activities of the antioxidant enzymes such as glutathione S-transferases (GST), superoxide dismutase (SOD) and catalase (CAT) (Zhang et al. 2019). The cellular cytophysiological actions are regulated by the balance between the antioxidant capacity and the production of reactive oxygen species (ROS) (Parellada et al. 2012). Antioxidants such as quercetin, Vc, VE, can protect cells by scavenging free radicals. Antioxidant system includes different types of components, both enzymatic and non-enzymatic. The SOD, glutathione peroxidase (GPx) are both antioxidant enzymes, and other enzymatic antioxidants such as CAT can quickly remove the ROS, which can protect the body from their harmful effects (Li et al. 2013). However, how the TPT toxicity inhibits the antioxidants and the quercetin alleviate this response are not clear.

Apoptosis is the death process of cells in response to the physiological and pathological stimulus signal that plays a crucial role in the health of fish. It is an indispensable component of various cellular processes that mediate the phagocytosis to remove dying or infected cells, and remodel the flamed sites by reducing the release of pro-inflammatory cytokines (Luo et al. 2017). Apoptosis is strictly regulated. Many factors including pro-apoptotic factors (Bax, Casp-3 and Casp-9), anti-apoptotic factors such as Bcl-2 could affect the process of apoptosis. So, these genes could serve as indicators to study the effect of TPT in zebrafish liver and the ameliorating effect of quercetin.

Quercetin is an important bioactive compound found abundantly in many vegetables, fruits, fruit juices and herbal dietary supplements (Wach et al. 2007). It is known to have anti-inflammatory, antioxidant, neuro-protection, anti-carcinogenic, antidiabetic, and anti-proliferative effects in vitro and in vivo (Meng et al. 2018; Dokumacioglu et al. 2018; Laura et al. 2018). In one study, quercetin was reported to scavenge ROS and can effectively inhibit neuronal damage by regulating the oxidative stress (Adedara et al. 2017). In addition, quercetin is considered to be a natural flavonoid for the prevention of hepatotoxicity (Oliveira et al. 2014). However, the molecular mechanisms of TPT-induced liver injury and protective effects of quercetin are not yet completely understood. The aim of this study was to fill these gaps. Thus, the antioxidant and anti-inflammatory capability of quercetin were evaluated in this study. In general, this research contributes to a better understanding of the regulatory of quercetin and its role in the management of liver injury.

\section{Materials And Methods}

\subsection{TPT and quercetin}

In this experience, TPT chloride (98\%) was obtained from Sigma-Aldrich (USA). The concentrations of TPT was $10 \mu \mathrm{g} \mathrm{Sn} / \mathrm{mL}(33.1 \mathrm{n} \mathrm{M} / \mathrm{mL}$ ), which was prepared in the $95 \%$ ethanol. At the time of exposure, the solutions were added directly to the water. Quercetin was also purchased from Sigma-Aldrich with a purity more than or equal to $95 \%$.

\subsection{Experimental diets}


The proximate composition and ingredients of the basal diets are shown in Table 1. The dosage of quercetin was $100 \mathrm{mg} / \mathrm{kg}$ and then was mixed with the basal diet. The feed material were ground into fine powder with a shredder, and then mixed with appropriate water to form a soft dough. The dough was granulated (no steam injected) using a $0.3 \mathrm{~mm}$ diameter pellet grind. The experimental feed was dried overnight at $50^{\circ} \mathrm{C}$ and stored in airtight bags at $4^{\circ} \mathrm{C}$ until use.

Table 1

Ingredients and proximate composition of the basal diet.

\begin{tabular}{|c|c|c|c|}
\hline Ingredients & $(\%)$ & proximate composition & (\% air-dry basis) \\
\hline Fish meal & 8 & Moisture & 11.32 \\
\hline Soybean meal & 30 & Crude protein & 33.42 \\
\hline Cottonseed meal & 16 & Crude lipid & 6.28 \\
\hline Rapeseed meal & 16 & Energy $(\mathrm{MJ} / \mathrm{Kg})$ & 14.26 \\
\hline Soybean oil & 2 & & \\
\hline Fish oil & 2 & & \\
\hline Wheat bran & 5 & & \\
\hline Wheat flour & 18 & & \\
\hline $\mathrm{Ca}\left(\mathrm{H}_{2} \mathrm{PO} 4\right)_{2}$ & 1.8 & & \\
\hline Premix & 1 & & \\
\hline $\mathrm{NaCl}$ & 0.2 & & \\
\hline \multicolumn{4}{|c|}{ 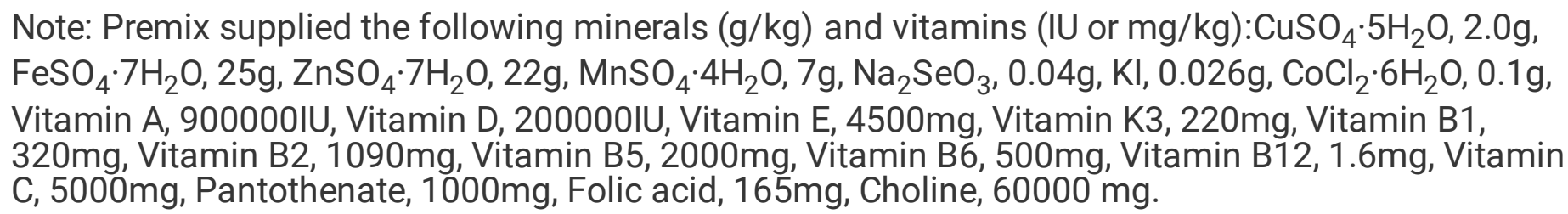 } \\
\hline
\end{tabular}

\subsection{Fish and experimental design}

Zebrafish were provided from a commercial fish dealer (Guangzhou, China). Before the feeding trial, fish were acclimated for two weeks at the Aquarium Science Laboratory in Henan University of Science and Technology. During the period of acclimation, the fish were feeding a commercial diet with two times per day, which contained $11.32 \%$ moisture, $33.42 \%$ crude protein and $6.28 \%$ crude lipid. After the acclimation, the fish were starved for $48 \mathrm{~h}$. Fish were randomly distributed into four groups, each with 60 fish. Every tank was placed 20 fish (mean weight of $2.05 \mathrm{~g} \pm 0.03 \mathrm{~g}$ ) in $60 \mathrm{~L}$ glass tanks. The tank contains $40 \mathrm{~L}$ dechlorinated tap water. The control group was fed the basal diet (D1) and the following three treatments were implemented. D2: fish fed with basal diet and exposed in $10 \mathrm{ng} / \mathrm{L}$ TPT. D3: fish fed with 
experimental diets and exposed in $10 \mathrm{ng} / \mathrm{L} \mathrm{TPT}$. D4: fish fed with experimental diets. In the process of experiment, fish were fed twice a day at 7:30, $18: 30$ respectively and water was exchanged by $25 \%$ daily at $8: 30$. The experiment lasted for 8 weeks. Water temperature was controlled at $26^{\circ} \mathrm{C}$ to $27^{\circ} \mathrm{C}$. $\mathrm{pH}: 7.0$ -7.5 , The dissolved oxygen was maintained approximately at $6.0 \mathrm{mg} / \mathrm{L}$.

\section{Sampling procedure}

The fish were anaesthetized by MS-222 (pH 7.6, ethyl 3-aminobenzoatemethane-sulphonic acid, $1 \mathrm{~g} / \mathrm{L}$ ). Fish were dissected on ice. The livers were removed, frozen in liquid nitrogen and stored at $-80^{\circ} \mathrm{C}$ for further enzymological assays and RNA quantification.

\subsection{Assessment of oxidative stress}

Frozen liver tissues were homogenized in $0.5 \mathrm{~mL}$ ice-cold $0.86 \%$ physiological saline with $10 \mathrm{x}$ volume $(\mathrm{pH}=7.4)$ and centrifuged at $12,000 \mathrm{~g}$ for $10 \mathrm{~min}$ at $4^{\circ} \mathrm{C}$. Then, supernatants were collected for various biochemical analyses. Oxidative stress induced by TPT was examined via measures of the MDA and NO levels. The MDA level was measured using the thiobarbituric acid. The quantification of NO release was detected by DAF FM DA fluorescence assay as described Choi (Choi et al.2012). The glutathione (GSH) level was determined using the method of Sedlak and Lindsay with some modifications (Sedlak and Lindsay 1968). The GSH levels were expressed as $\mathrm{nmol} / \mathrm{g}$ tissue. The activity of SOD was measured using a SOD kit (Randox labs. Crumlin, UK), as described by Breinholt et.al (Breinholt et al. 2000). The activities of GPx and CAT were determined with the detection kits (Nanjing Jian-Cheng Bioengineering Institute, China) according to the manufacturer's protocol. Using bovine serum albumin as a standard, the total protein concentrations in the supernatants were determined by Bradford method (Bradford 1976).

\subsection{Gene expression analysis}

Total RNA was isolated from the hepatopancreas using TRIzol reagent (Takara), following the manufacturer's instructions. Using a Nanodrop 1000 spectrophotometer (Thermo Scientific, USA) determined the RNA concentration by obtaining the UV absorbance at $260 \mathrm{~nm}$. The absorbance ratio at $260 \mathrm{~nm} / 280 \mathrm{~nm}$ was determined to evaluate the RNA Purity. cDNA was synthesized from RNA with the Revert Aid First Strand cDNA Synthesis Kit (Thermo Scientific, USA). The reaction tube was placed on the PCR amplification instrument for $60 \mathrm{~min}$ at $37^{\circ} \mathrm{C}$ and $15 \mathrm{~min}$ at $70^{\circ} \mathrm{C}$ for denaturation. The reverse transcripts were stored at $4^{\circ} \mathrm{C}$ for later use.

The TNF-a, IL-1 $\beta$, IL-8, NF- kBp65, IL-10 and IkB, Casp-3, Casp-9, Bax and Bcl-2 expression were determined using Real-time PCR. PCR was performed using a 7300 Real-Time PCR System (Applied Biosystems) in 96-well plates (Axygen). The reaction system contained $20 \mu \mathrm{L}$ mixtures using SYBR Green I dye. PCR amplifications contained $1 \mu \mathrm{L}$ cDNA template, $1 \mu \mathrm{L}$ forward and reverse primers (concentration of $1 \mathrm{pM}$ ), $6.8 \mu \mathrm{L}$ of SYBR green PCR master mix and $10.2 \mu \mathrm{L}$ nuclease-free water and. The PCR reaction tube was put into the DNA amplification instrument for $94{ }^{\circ} \mathrm{C}$ for $4 \mathrm{~min}$, and then the thermal cycle was carried out under the following conditions: $95^{\circ} \mathrm{C}$ for $45 \mathrm{~s}, 57^{\circ} \mathrm{C}$ for $1 \mathrm{~min}, 72{ }^{\circ} \mathrm{C}$ for $1 \mathrm{~min}$. The PCR was carried out for 40 cycles. Details of primers used in this study were shown in Table 2. Genes expression 
was expressed as multiple change relative to the control. They were calculated by $2^{-\Delta \Delta C t}$ method with three replicates for treatment (Livak and Schmittgen). The expression profiles of target genes were normalized with $\beta$-actin (housekeeping or conserved gene).

Table 2

Primers used in this study.

\begin{tabular}{|c|c|c|}
\hline Primer & Sequence( $\left(5^{\prime}-3^{\prime}\right)$ & GenBank accession no. \\
\hline $\mathrm{Bcl}-2 \mathrm{~F} 1$ & TGGCTACAGCGACAGCTCTG & NM_200317.1 \\
\hline Bcl-2R1 & GCATTCCAGCGTTCTCTCGA & NP_001116737.1 \\
\hline Bax F1 & AGGGCTTCACTCTCTGCAAC & AY735397.1 \\
\hline Bax R1 & CACACTGTGCAGCAGGTTTC & \multirow[t]{5}{*}{ AB018218.1 } \\
\hline Caspase3F1 & CCTTGCGTGGTCACTACACT & \\
\hline Caspase3R1 & CACCTGGAGCCTACAACCTG & \\
\hline Caspase9F1 & TCGCTGCTTCTTCTGTCAGG & \\
\hline Caspase9R1 & ACAGCCGTCCATTTTGGCTT & \\
\hline TNF-aF1 & CTGCTTCACGCTCCATAAGA & \multirow[t]{2}{*}{ AY427649.1 } \\
\hline TNF-aR1 & GCCTGGTCCTGGTCATCTC & \\
\hline IL-8F1 & GGTGAGAGACGGAGAGATGGAT & \multirow[t]{2}{*}{ JN698962.1 } \\
\hline IL-8R1 & CACGCTGGAGAAGTTGAACAG & \\
\hline IL-1ßF1 & ACAGAATGAAGCACATCAAACC & AY340959.1 \\
\hline IL-1ßF1 & ACAGAATGAAGCACATCAAACC & \\
\hline NF-kB P65F1 & GGCAGGTGGCGATAGTGTT & \multirow[t]{2}{*}{ AY735398.1 } \\
\hline NF-кB P65R1 & САTTCCTTCAGTTCTCTTGCG & \\
\hline IL-10F1 & GCAGGCCTGACCCTACATTT & \multirow[t]{2}{*}{ NM_001171592.1 } \\
\hline IL-10R1 & CCCCAGTGGAACACAGAGTC & \\
\hline IkBaF1 & CAAACTGGTGGTTCAAGCCG & \multirow[t]{2}{*}{ NM_001123265.1 } \\
\hline IkBaR1 & САCTCACTGGACTGCGAACT & \\
\hline$\beta$-actinF1 & TCGTCCACCGCAAATGCTTCTA & \multirow[t]{2}{*}{ AY222742.1 } \\
\hline$\beta$-actinR1 & CCGTCACCTTCACCGTTCCAGT & \\
\hline
\end{tabular}

\subsection{Statistical analysis}


SPSS 18.0 software (SPSS, Chicago, IL, USA) was used to analyze the data. The results of treatments significantly differed from the control group were performed with One-way analysis of variance following Tukey's test. The results of analysis are presented as Means \pm S.D. P values $<0.05$ were accepted as significant.

\section{Results}

\subsection{Effects of TPT and quercetin on hepatic oxidative damage parameters in the liver of zebrafish}

The effects of TPT and treatment with quercetin and their combination on lipid peroxidation and liver oxidative parameters are shown in Fig. 1. After exposure to TPT, the levels of MDA and NO were significantly increased, while GSH, GPX, SOD and CAT levels were significantly decreased compared with these indexes in control group $(P<0.05)$. However, the dietary quercetin significantly $(P<0.05)$ reduced the toxic effects of TPT on hepatic GSH, GPx, SOD, CAT, MDA and NO, and these values were higher or lower $(P<0.05)$ than the TPT group values. Interestingly, quercetin group showed significant elevation in the SOD and GSH levels compared with control group $(P<0.05)$.

\subsection{Effects TPT and quercetin on apoptosis-related gene expression in the liver of zebrafish}

The effects of quercetin on TPT-induced Bcl-2, Bax, caspase3 and caspase9 mRNA expression changes are shown in Fig. 3. Compared with the control treatment, TPT treatment significantly increased the mRNA expression of Bax, caspase3, and caspase9, while significantly decreased the expression level of $\mathrm{Bcl}-2(P<0.05)$. However, dietary quercetin prevented a marked increase in liver Bax, caspase3 and caspase9 mRNA expression induced by TPT exposure, but increased Bcl-2 mRNA levels $(P<0.05)$.

\subsection{Effects TPT and quercetin on inflammatory response-related gene expression in the liver of zebrafish.}

The effects of TPT and treatment with quercetin on inflammatory response-related gene expression are shown in Fig. 2. Compared with the control group, TPT significantly increased the levels of TNF-a, IL-8, IL$1 \beta$ and NF- kBp65 mRNA expression levels of in zebrafish liver $(P<0.05)$. However, compared with the TPT group, dietary quercetin significantly decreased the mRNA expression levels of TNF-a, IL-8, IL-1 $\beta$ and NF- kBp65. The IL-10 and IkB mRNA expression were down-regulated by TPT exposure $(P<0.05)$. Quercetin decreased the changes in the expression of IL-10 and IkB decreased by TPT. In addition, administration of quercetin alone showed no significant difference $(P>0.05)$ compared to control groups (Fig. 3).

\section{Discussion}

Oxidative stress is unbalanced between the oxidation and antioxidation, which is considered an important role in many pathological and physiological phenomena of the body. Concerning oxidative stress indices, our study showed that fish exposure to TPT had significantly higher levels of the MDA and NO in liver tissue in zebrafish. On the other hand, MDA levels in liver tissues decreased after the application of $100 \mathrm{mg} / \mathrm{kg}$ quercetin compared to the TPT group. MDA is a scientifically recognized 
indicator of oxidative stress, which is the product of polyunsaturated fatty acid peroxidation (Parvez and Raisuddin 2005). MDA levels rise when oxidative stress occurs (Del 2005). In general, the decrease of GSH level or GSH/GSSG ratio can express excess ROS (Jeroen et al. 2015). The liver synthesizes key enzymes that remove ROS and produce the systemic antioxidants, including GSH, SOD, GPx and CAT (Todorova et al 2005). Antioxidant enzymes are considered as the main defense system to inhibit the production of ROS and protect macromolecules from oxidative damage. SOD and GSH are the main antioxidant enzymes in the liver, and are also the main elements to enhance immunity to prevent diseases. While GPx is the main protective enzyme that can effectively scavenge free radicals in organisms, thus protecting cells from oxidative damage (Yildirim and Kilic 2011). In the present study, the antioxidant enzymes were examined after exposure to TPT. Based on the obtained results, it was shown that GSH level, GPx, SOD and CAT activities decreased in the TPT group. However, these enzyme activities in fish fed $100 \mathrm{mg} / \mathrm{kg}$ quercetin were significantly increased in liver tissue. These results suggest that quercetin can protect liver against TPT-induced oxidative stress by regulating antioxidant enzyme activities. Quercetin effectively mitigates oxidative status by reducing lipid peroxidation and increasing various antioxidant enzymes in the liver of zebrafish. In previous study, quercetin could also scavenge oxidative radicals and increase the level of antioxidant defense (Livingstone 2001). In previous study, it was reported that quercetin increased the level of GSH, decreased the ROS and MDA levels, and regulated antioxidant enzyme activities in ethanol-exposure rats (Molina et al. 2003). Consistent with our experiment, a study showed that quercetin can elevate SOD and GPx activities and ameliorate MDA level (Adedara et al. 2017). Quercetin sweep free radicals off and thereby reduces oxidative and cytotoxic effects may be due to its molecular structure including several hydroxyls which can interact with free radicals to inhibit oxidative stress (Zhang et al. 2019). Whereas in another study, it was reported that quercetin attenuated the increases of antioxdant activities induced by dichlorvos (Salem et al. 2015). These different results might be related to animal species, breed conditions and animal state. This study demonstrated that dietary quercetin can effectively inhibit oxidative stress caused by free radicals.

The hepatotoxicity of TPT is closely related to the formation and apoptosis of ROS in hepatocytes. The production of oxidative stress and ROS are important signals of apoptosis (Todorova et al. 2005). The increased levels of ROS might impair the mitochondria functions, including changes of mitochondrial permeability, respiration and oxidative phosphorylation. Then, The mitochondria release cytochrome $\mathrm{C}$, which activates caspase-3 and caspase-9, leading to cell apoptosis (Chen et al. 2014). It has also been reported that ROS mediate the mitochondria-dependent apoptosis in a variety of cells (Singh et al. 2007). Additionally, oxidative stress can damage DNA and directly or indirectly cause cell apoptosis (Tyor and Pahwa 2017). Bcl-2 is an anti-apoptotic gene and can inhibit cell apoptosis by preventing the release of cytochrome $\mathrm{c}$ from mitochondria. But Bax induce release of cytochrome $\mathrm{c}$ to trigger a pro-apoptotic pathway (Deng et al. 2009). If the Bax/Bcl2 ratio increases, it indicates the induction of cell apoptosis (Whiteman et al. 2007). In this study, it showed that several apoptotic related genes, such as Bax, caspase 3 and caspase9, were up-regulated, while the mRNA expression of anti-apoptotic Bcl2 genes was decreased in the TPT group. We hypothesize that TPT lead to liver cell apoptosis by inducing of oxidative and activating p53 expression, which leads to the transcription of genes encoding pro-apoptotic proteins. 
Cas3 (caspase-3) plays an irreplaceable role in cell apoptosis, which could be activated by Cas9 (caspase-9) and is a very important terminal splicing enzyme in the process of apoptosis (Deng et al. 2009). However, dietary quercetin attenuated cell apoptosis with downregulation of Bax, Casp-3 and Casp-9 as well as upregulation of Bcl-2. Quercetin has anti-apoptosis effect in various tissues (Kumar et al. 2014; Hu et al. 2015; Lei et al. 2015). Similar results were also found that $100 \mu \mathrm{M}$ of quercetin decreased apoptosis, while $1000 \mu \mathrm{M}$ of quercetin increased apoptosis (Ahn and Jeon 2015). We suggested that in the dietary quercetin group, the decrease of apoptosis might be related to the restrain of pro-inflammatory cytokines in liver. However, the underlying mechanism in fish remains unclear, which require further research.

Numerous researches have shown that organotin caused inflammation and pathological alterations (Zhang et al. 2015; Zhang et al. 2017; Zhang et al. 2018). TNF-a, IL-1 $\beta$ and IL-8 are major proinflammatory cytokines and, they are often used as markers of the inflammatory response (Secombes 2016). But the anti-inflammatory cytokines, such as IL-10 and TGF, may reduce the overreaction on inflammatory response in fish (Kemenade et al. 2009). Paralleled with the oxidative stress parameters, the TNF-a, IL-8 and IL-1 $\beta$ mRNA levels were significantly increased compared to the control. But, dietary quercetin remarkably alleviated the inflammatory response induced by TPT, showing lower gene expressions of pro-inflammatory cytokines, indicating that quercetin might alleviate the inflammation in the liver of fish. Although several previous studies indicated that quercetin attenuated animal inflammation mediated by inhibiting the expression of pro-inflammation gene (Julie et al. 2012; Mehta et al 2017). No studies of the possible effects of quercetin on fish have been reported. The quercetin regulated the pro-inflammatory cytokines, which might be related to the related signaling such as NF-kB. NF-kB plays an important role in the regulation of pro-inflammatory cytokines such as IL-8 and TNF-a (Neurath and Pettersson 1997). In this study, compared with the TPT group, quercetin decreased the mRNA expression of NF- kB p65 in the liver of zebrafish. Further contrastive analysis showed that the TNF-a, IL-1 $\beta$ and IL-8 were positively correlated with the mRNA expression of NF-kB p65, which suggested that quercetin inhibited the levels of TNF-a, IL-1 $\beta$ and IL-8 might be related to the decrease of NF- $k B$ gene expression. In addition, NF- kB inhibitor protein (IkB) can directly inhibit NF- kB in fish (Iwasaki et al. 2011). In mice, it has been reported that the up-regulation of NF- kB mRNA was regulated by the downregulation of IkB gene expression (Beg et al. 1995). In this study, the author firstly showed that TPT downregulated IkB mRNA levels in the liver of zebrafish, where quercetin up-regulated this gene. Further analysis indicated that the IL-8, TNF-a mRNA levels and NF- kB p65 were negatively correlated with the IkB mRNA levels, suggesting that quercetin might be through up-regulation the IkB mRNA level and downregulation the NF-kB mRNA level to prevent inflammatory response in fish. Similar results were also observed in mice (Jung et al 2012).

This result indicated that TPT exposure could induce accumulation of MDA and NO in tissue, inhibiting the antioxidant system. Quercetin could protect the zebrafish liver against TPT-induced injury by decreasing ROS production, alleviating cell apoptosis, renewing antioxidant enzymes activities, and attenuating inflammation. 


\section{Declarations}

\section{Acknowledgments}

This work was funded by the National Natural Science Foundation (China, 32002405) and the Henan Natural Science Foundation (182300410032).

\section{Author Declarations}

The authors declare that they have no known competing financial interests or personal relationships that could have appeared to influence the work reported in this paper.

The procedures of this study involving animals and their care were approved by the Animal Care and Use Committee of Henan University of Scientific and Technology (the number of committees was 9).

The data and materials are ture and they are available in the manuscript.

\section{Authors' contributions}

Chuannuan Zhang: Conceptualization, Methodology, Writing, Reviewing, Editing and Revising. Yuheng Wang: Data curation, Writing, Original draft preparation and Revising. Hongtao Ren: Investigation, Writing - Reviewing. Junhui Wang: Resources, Writing - Reviewing. Dongxue Jiang and Xiaoyu Yuan: Project administration, Writing- Reviewing.

\section{References}

Adedara IA, Ego VC, Subair TI, Oyediran O, Farombi EO (2017) Quercetin improves neurobehavioral performance through restoration of brain antioxidant status and acetylcholinesterase activity in manganese-treated rats. Neurochem Res 42:1219-1229.

Ahn TB, Jeon BS (2015) The role of quercetin on the survival of neuron-like PC12 cells and the expression ofa-synuclein. Neural Regen Res 10:1113-1119. https://doi.org/ 10.4103/1673-5374.160106

Beg AA, Sha WC, Bronson RT, Baltimore D (1995) Constitutive NF-kappa B activation, enhanced granulopoiesis, and neonatal lethality in I kappa B alpha-deficient mice. Gene Dev 9:2736-2746. https://doi.org/ 10.1101/gad.9.22.2736

Bradford MMA (1976) Rapid and sensitive method for the quantitation of microgram quantities of protein utilizing the principle of protein-dye binding. Anal Biochem 72:248-254. https://doi.org/ 10.1016/00032697(76)90527-3

Breinholt V, Lauridsen ST, Dragsted LO (2000) Differential effects of dietary flavonoids on drug metabolizing and antioxidant enzymes in female rat. Xenobiotica 29:1227-1240. https://doi.org/ $10.1080 / 004982599237903$ 
Chen C, Huang Q, Chen Z, Zhang W (2019) Organotin contamination in commercial and wild oysters from China: Increasing occurrence of triphenyltin. Sci Total Environ 650:2527-2534. https://doi.org/ 10.1016/j.scitotenv.2018.09.310

Chen JW, Ni BB, Li B, Yang YH, Jiang SD, Jiang LS (2014) The responses of autophagy and apoptosis to oxidative stress in nucleus pulposus cells: implications for disc degeneration. Cell Physiol Biochem 34:1175-1189. https://doi.org/ 10.1159/000366330

Choi SJ, Tai BH, Cuong NM, Kim YH, Jang HD (2012) Antioxidative and anti-inflammatory effect of quercetin and its glycosides isolated from mampat (Cratoxylum formosum). Food Sci Biotechnol 21: 587595. https://doi.org/ 10.1007/s10068-012-0075-4

Clasen B, Becker AG, Lópes T, Murussi CR, Antes FG, Horn RC, Flores M M, Baldisserotto BD, Valderi L, Loro VL (2017) Triphenyltin hydroxide induces changes in the oxidative stress parameters of fish. Ecotoxicology 26:565-569. https://doi.org/ 10.1007/s10646-017-1780-9

Del RD, Stewart WJ, Pellegrini N (2005) A review of recent studies on malondialdehyde as toxic molecule and biological marker of oxidative stress. Nutr Metab Cardiovas Dis 15: 316-328. https://doi.org/ 10.1016/j.numecd.2005.05.003

Deng J, Yu L, Liu C, Yu K, Shi X, Yeung LWY., Paul K S, Lam R S, Wu S, Zhou BS (2009) Hexabromocyclododecane-induced developmental toxicity and apoptosis in zebrafish embryos. Aquat Toxicol 93:29-36. https://doi.org/ 10.1016/j.aquatox.2009.03.001

Dokumacioglu E, Iskender H, Sen T, Ince I, Saral S (2018) The effects of hesperidin and quercetin on serum tumor necrosis factor-alpha and interleukin-6 levels in streptozotocin-induced diabetes model. Pharmacogn Mag 14:167-173. https://doi.org/ 10.4103/pm.pm_41_17

Gao JM, Wu L, Chen YP, Zhou B, Guo JS, Zhang K, Ouyang WJ (2017) Spatiotemporal distribution and risk assessment of organotins in the surface water of the Three Gorges Reservoir Region, China. Chemosphere 171, 405-414. https://doi.org/ 10.1016/j.chemosphere.2016.12.089

Hoch M (2001) Organotin compounds in the environment: an overview. Appl Geochem 16: 719-743. https://doi.org/ 10.1016/S0883-2927(00)00067-6

Hu J, Yu QW, Zhao F, Ji JZ, Jiang ZZ, Chen X, Gao P, Ren YR, Shao S, Zhang LY, Yan M (2015) Protection of quercetin against Triptolide-induced apoptosis by suppressing oxidative stress in rat Leydig cells. Chem Biol Interact 240:38-46. https://doi.org/ 10.1016/j.cbi.2015.08.004

Iwasaki H, Takeuchi O, Teraguchi S, Matsushita K, Uehata T, Kuniyoshi K, Satoch T, Matsushita M, Akira S (2011) The IKB kinase complex regulates the stability of cytokine-encoding mRNA induced by TLR-IL-1R by controlling degradation of regnase-1. Nat Immunol 12:1167-1175. https://doi.org/ 10.1038/ni.2137 
Jeroen F, Paul Graham W, Neven Z, Sean D, Roland S, David C, Knight AR, Taulor EL, Oettrich J, Ruskovska T, Gasparovic AC, Cuadrado A, Weber D, Poulsen HE, Grune T, Schmidt HHW, Ghezzi P (2015) Clinical relevance of biomarkers of oxidative stress. Antioxid Redox Sign 23:1144-1170. https://doi.org/ $10.1089 /$ ars. 2015.6317

Julie B, Marilyn P, Justine R, Cindy P, Maria-Grazia M (2012) Quercetin and sesamin protect dopaminergic cells from MPP +-induced neuroinflammation in a microglial (N9)-Neuronal (PC12) coculture system. Oxid Med Cell Longev 12:1-11. https://doi.org/ 10.1155/2012/921941

Jung JH, Kang Jl, Kim HS (2012) Effect of quercetin on impaired immune function in mice exposed to irradiation. Nutr Res Pract 6:301-307. https://doi.org/ 10.4162/nrp.2012.6.4.301

Kemenade V, Stolte BML, Metz EH, Chadzinska JR (2009) Neuroendocrine-immune interactions in teleost fish. Fish Physiol 28:313-364. https://doi.org/ http://hdl.handle.net/2066/75409

Kennedy G, Spence VA, Mclaren M, Hill A, Underwood C, Belch JJF (2005) Oxidative stress levels are raised in chronic fatigue syndrome and are associated with clinical symptoms. Free Radical Bio Med 39:584-589. https://doi.org/ 10.1016/j.freeradbiomed.2005.04.020

Kumar B, Gupta SK, Nag TC, Srivastava S, Saxena R, Jha KA, Srinivasan BP (2014) Retinal neuroprotective effects of quercetin in streptozotocin-induced diabetic rats. Exp Eye Res 125:193-202. https://doi.org/ 10.1016/j.exer.2014.06.009

Laura F, Natalie L, Laura S, Tara H (2018) Dietary quercetin attenuates adipose tissue expansion and inflammation and alters adipocyte morphology in a tissue-specific manner. Int J Mol Sci 19: 895-901. https://doi.org/ 10.3390/ijms19030895

Lee CC, Hsu YC, Kao YT, Chen HL (2016) Health risk assessment of the intake of butyltin and phenyltin compounds from fish and seafood in Taiwanese population. Chemosphere 164: 568-575. https://doi.org/ 10.1016/j.chemosphere.2016.08.141

Lei X, Chao H, Zhang Z, Lv J, Li S, Wei H, Xue R, Li F, Li Z (2015) Neuroprotective effects of quercetin in a mouse model of brain ischemic/reperfusion injury via anti? apoptotic mechanisms based on the Akt pathway. Mol Med Rep 12:3688-3696. https://doi.org/ 10.3892/mmr.2015.3857

Li HT, Feng L, Jiang WD, Liu Y, Jiang J, Li SH, Zhou XQ (2013) Oxidative stress parameters and antiapoptotic response to hydroxyl radicals in fish erythrocytes: Protective effects of glutamine, alanine, citrulline and proline. Aquat Toxicol 126:169-179. https://doi.org/10.1016/j.aquatox.2012.11.005

Livak K, Schmittgen T (2001) Analysis of relative gene expression data using real-time quantitative PCR and the $2^{-\triangle \Delta C t}$ Method. Methods 25:402-408. https://doi.org/ 10.1006/meth.2001 
Livingstone DR (2001) Contaminant-stimulated reactive oxygen species production and oxidative damage in aquatic organisms. Mar Pollut Bull 42: 656-666. https://doi.org/ 10.1016/S0025326X(01)00060-1

Lu J, Feng J, Cai S, Chen Z (2016) Metabolomic responses of Haliotis diversicolor to organotin compounds. Chemosphere 168:860-869. https://doi.org/ 10.1016/j.chemosphere. 2016.10.124

Luo SW, Kang H, Kong JR, Xie RC, Liu Y, Wang WN, Xie FX, Sun ZM (2017) Molecular cloning, characterization and expression analysis of (B-cell lymphoma-2) Bcl-2 in the orange-spotted grouper (Epinephelus coioides). Dev Comp Immunol 76:150-162. https://doi.org/10.1016/j.dci.2017.06.003

Mehta V, Parashar A, Udayabanu M (2017) Quercetin prevents chronic unpredictable stress induced behavioral dysfunction in mice by alleviating hippocampal oxidative and inflammatory stress. Physiol Behav 171:69-78. https://doi.org/ 10.1016/j.physbeh.2017.01.006

Meng LQ, Yang FY, Wang MS, Shi BK, Chen DX, Chen D, Zhou Q, He QB, Ma LX, Cheng WL Xing NZ (2018). Quercetin protects against chronic prostatitis in rat model through NF-KB and MAPK signaling pathways. Prostate 78:790-800. https://doi.org/ 10.1002/pros.23536

Molina MF, Sanchez-Reus I, Iglesias I, Benedi J (2003) Quercetin, a flavonoid antioxidant, prevents and protects against ethanol-induced oxidative stress in mouse liver. Biol Pharma Bull 26:1398-1402. https://doi.org/ 10.1248/bpb.26.1398

Neurath MF, Pettersson S (1997) Predominant role of NF-KB p65 in the pathogenesis of chronic intestinal inflammation. Immunobiology 198:0-98. https://doi.org/ 10.1016/S0171-2985(97)80030-7

Oliveira CRD, Ceolin J, Oliveira RRD, Schemitt EG, Marroni NP (2014) Effects of quercetin on polychlorinated biphenyls-induced liver injury in rats. Nutricion Hospitalaria Organo Oficial De La Sociedad Espanola De Nutricion Parenteral Y Enteral 29:1141-1148. https://doi.org/ 10.3305/nh.2014.29.5.7362

Parellada M, Moreno C, Mac-Dowell K, Leza JC, Giraldez M, Bailón C, Castro C, Miranda-Azpiazu P, Frausas D, Arango C (2012) Plasma antioxidant capacity is reduced in Asperger syndrome. J Psychiat Res 46:394-401. https://doi.org/ 10.1016/j.jpsychires.2011.10.004

Parvez S, Raisuddin S (2005) Protein carbonyls: novel biomarkers of exposure to oxidative stressinducing pesticides in freshwater fish Channa punctata (Bloch). Environ Toxicol Pharmacol 20:112-117.

Patten DA, Germain M, Kelly A, Slack RS (2010) Reactive oxygen species: stuck in the middle of neurodegeneration. J Alzheimers Dis 20:S357-367. https://doi.org/ 10.3233/JAD-2010-100498

Salem IB, Boussabbeh M, Graist I, Rhouma A, Bacha H, Essefi SA (2015) Quercetin protects HCT116 cells from Dichlorvos-induced oxidative stress and apoptosis. Cell Stress Chap 21:179-186. https://doi.org/ $10.1007 / \mathrm{s} 12192-015-0651-7$ 
Secombes JC (2016) What's new in fish cytokine research? Fish Shellfish Immunol 53: 1-3. https://doi.org/ 10.1016/j.fsi.2016.03.035

Sedlak J, Lindsay RH (1968) Estimation of total protein bound and non-protein sulphhydryl group in tissue with Ellman Reagent. Analyt Biochem 25:192-205.

Singh M, Sharma H, Singh N (2007) Hydrogen peroxide induces apoptosis in HeLa cells through mitochondrial pathway. Mitochondrion 7:367-373. https://doi.org/ 10.1016/j.mito.2007.07.003

Todorova I, Simeonova G, Kyuchukova D, Dinev D, Gadjeva V (2005) Reference values of oxidative stress parameters (MDA, SOD, CAT) in dogs and cats. Comp Clin Pathol 13:190-194. https://doi.org/ $10.1007 / \mathrm{s} 00580-005-0547-5$

Tyor AK, Pahwa K (2017) Pollutants induced oxidative stress, DNA damage and cellular deformities in clarias gariepinus (Burchell), from River Yamuna in Delhi Region, India. B Environ Contam Tox 99:33-38.

Wach A, Pyrzynska K, Biesaga M (2007) Quercetin content in some food and herbal samples. Food Chem 100: 699-704. https://doi.org/ 10.1016/j.foodchem.2005.10.028

Wen JJ, Cui XY, Gibson M, Li ZY (2018) Water quality criteria derivation and ecological risk assessment for triphenyltin in China. Environ Saf 161:397-401. https://doi.org/ 10.1016/j.ecoenv.2018.06.012

Whiteman M, Chu SH, Siau JL, Rose P, Sabapathy K, Schantz JT, Cheung NS, Spencer JPE, Armstrong JS (2007) The pro-inflammatory oxidant hypochlorous acid induces Bax-dependent mitochondrial permeabilisation and cell death through AIF-/EndoG-dependent pathways. Cell Signal 19:705-714. https://doi.org/ 10.1016/j.cellsig.2006.08.019

Xu J, Li M, Mak NK, Chen F, Jiang Y (2011) Triphenyltin induced growth inhibition and antioxidative responses in the green microalga Scenedesmus quadricauda. Ecotoxicology 20: 73-80. https://doi.org/ $10.1007 / \mathrm{s} 10646-010-0557-1$

Yi AX, Han J, Lee JS, Leung KMY (2014) Ecotoxicity of triphenyltin on the marine copepod Tigriopus japonicusat various biological organisations: from molecular to population-level effects. Ecotoxicology 23:1314-1325. https://doi.org/ 10.1007/s10646-014-1274-y

Yi AX, Han J, Lee JS, Leung KMY (2016) Toxicity of triphenyltin chloride to the rotifer Brachionus koreanus across different levels of biological organization. Environ Toxicol 31:13-23. https://doi.org/ 10.1002/tox.22018

Yildirim Z, Kilic N (2011) Effects of taurine and age on cerebellum antioxidant status and oxidative stress. Int J Gerontol 5:166-170. https://doi.org/ 10.1016/j.ijge.2011.09.019

Zhang CN, Zhan JL, Ren HT, Zhou BH, Wu QJ, Sun P (2017) Effect of tributyltin on antioxidant ability and immune responses of zebrafish (Danio rerio). Ecotoxl Environ Saf 138:1-8. https://doi.org/ 
Zhang CN, Zhang JL, Huang Y, Ren HT, Guan SH, Zeng QH (2018) Dibutyltin depressed immune functions via NF-kappa B, and JAK/STAT signaling pathways in zebrafish (Danio rerio). Environ Toxicol 33:104-111.

Zhang J, Sun P, Kong T, Yang F, Guan W (2015) Tributyltin promoted hepatic steatosis in zebrafish (Danio rerio) and the molecular pathogenesis involved. Aquat Toxicol 170:2018-215. https://doi.org/

10.1016/j.aquatox.2015.11.028

Zhang JL, Zhang CN, Li EC, Jin MM, Huang MX, Cui W, Lin YY, Shi YJ (2019) Triphenyltin exposure affects mating behaviors and attractiveness to females during mating in male guppies (Poecilia reticulata). Ecotoxicol Environ Saf 169:76-84. https://doi.org/ 10.1016/j.ecoenv.2018.11.011

\section{Tables}

Table 1 Ingredients and proximate composition of the basal diet.

\begin{tabular}{llll}
\hline Ingredients & $(\%)$ & proximate composition & (\% air-dry basis) \\
\hline Fish meal & 8 & Moisture & 11.32 \\
Soybean meal & 30 & Crude protein & 33.42 \\
Cottonseed meal & 16 & Crude lipid & 6.28 \\
Rapeseed meal & 16 & Energy (MJ/Kg) & 14.26 \\
Soybean oil & 2 & & \\
Fish oil & 2 & & \\
Wheat bran & 5 & & \\
Wheat flour & 18 & & \\
Ca $\left(\mathrm{H}_{2} \mathrm{PO}\right)_{2}$ & 1.8 & & \\
Premix & 1 & & \\
NaCl & 0.2 & & \\
\hline
\end{tabular}

Note: Premix supplied the following minerals $\left(\mathrm{g} / \mathrm{kg}\right.$ ) and vitamins (IU or $\mathrm{mg} / \mathrm{kg}$ ): $\mathrm{CuSO}_{4} \cdot 5 \mathrm{H}_{2} \mathrm{O}, 2.0 \mathrm{~g}$, $\mathrm{FeSO}_{4} \cdot 7 \mathrm{H}_{2} \mathrm{O}, 25 \mathrm{~g}, \mathrm{ZnSO}_{4} \cdot 7 \mathrm{H}_{2} \mathrm{O}, 22 \mathrm{~g}, \mathrm{MnSO}_{4} \cdot 4 \mathrm{H}_{2} \mathrm{O}, 7 \mathrm{~g}, \mathrm{Na}_{2} \mathrm{SeO}_{3}, 0.04 \mathrm{~g}, \mathrm{KI}, 0.026 \mathrm{~g}, \mathrm{CoCl}_{2} \cdot 6 \mathrm{H}_{2} \mathrm{O}, 0.1 \mathrm{~g}$, Vitamin A, 900000IU, Vitamin D, 200000IU, Vitamin E, 4500mg, Vitamin K3 , 220mg, Vitamin B1, 320mg, Vitamin B2, 1090mg, Vitamin B5, 2000mg, Vitamin B6, 500mg, Vitamin B12, 1.6mg, Vitamin C, 5000mg, Pantothenate, 1000mg, Folic acid, 165mg, Choline, $60000 \mathrm{mg}$.

Table 2 Primers used in this study. 


\begin{tabular}{|c|c|c|}
\hline Primer & Sequence(5'-3') & GenBank accession no. \\
\hline Bcl-2 F1 & TGGCTACAGCGACAGCTCTG & NM_200317.1 \\
\hline Bcl-2R1 & GCATTCCAGCGTTCTCTCGA & NP_001116737.1 \\
\hline Bax F1 & AGGGCTTCACTCTCTGCAAC & \\
\hline Bax R1 & CACACTGTGCAGCAGGTTTC & AY735397.1 \\
\hline Caspase3F1 & CCTTGCGTGGTCACTACACT & \\
\hline Caspase3R1 & CACCTGGAGCCTACAACCTG & AB018218.1 \\
\hline Caspase9F1 & TCGCTGCTTCTTCTGTCAGG & \\
\hline Caspase9R1 & ACAGCCGTCCATTTTGGCTT & \\
\hline TNF- $\alpha$ F1 & CTGCTTCACGCTCCATAAGA & AY427649.1 \\
\hline TNF- $\alpha \mathrm{R} 1$ & GCCTGGTCCTGGTCATCTC & \\
\hline IL-8F1 & GGTGAGAGACGGAGAGATGGAT & JN698962.1 \\
\hline IL-8R1 & CACGCTGGAGAAGTTGAACAG & \\
\hline IL-1ßF1 & ACAGAATGAAGCACATCAAACC & AY340959.1 \\
\hline IL-1ßF1 & ACAGAATGAAGCACATCAAACC & \\
\hline NF-кB P65F1 & GGCAGGTGGCGATAGTGTT & AY735398.1 \\
\hline NF-кB P65R1 & САTTCСTTCAGTTCTCTTGCG & \\
\hline IL-10F1 & GCAGGCCTGACCCTACATTT & NM_001171592.1 \\
\hline IL-10R1 & CCCCAGTGGAACACAGAGTC & \\
\hline $\mathrm{IkB} \alpha \mathrm{F} 1$ & CAAACTGGTGGTTCAAGCCG & NM_001123265.1 \\
\hline $\mathrm{IkB} \alpha \mathrm{R} 1$ & CACTCACTGGACTGCGAACT & \\
\hline$\beta$-actinF1 & TCGTCCACCGCAAATGCTTCTA & AY222742.1 \\
\hline$\beta$-actinR1 & CCGTCACCTTCACCGTTCCAGT & \\
\hline
\end{tabular}

\section{Figures}


A

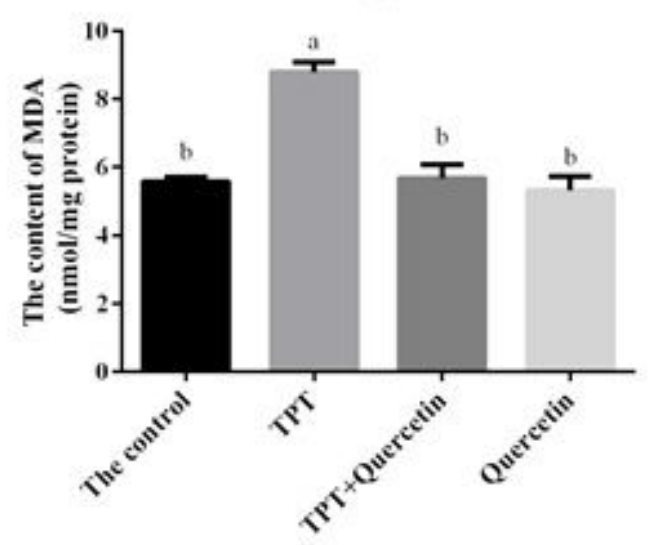

C

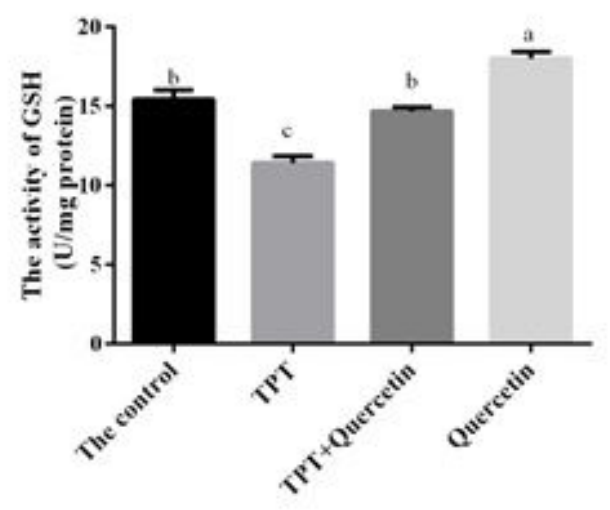

E

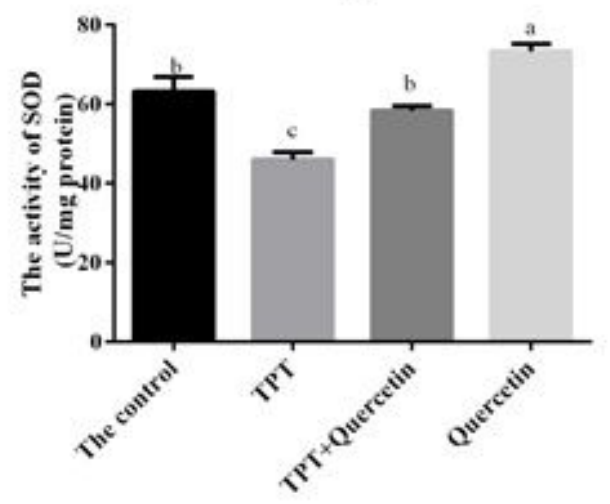

B

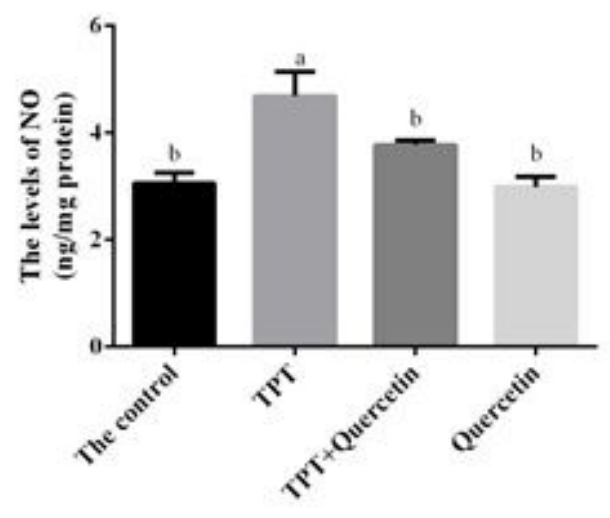

D

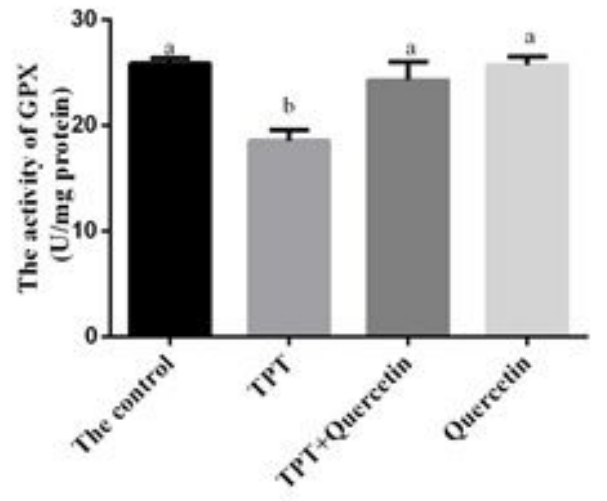

F

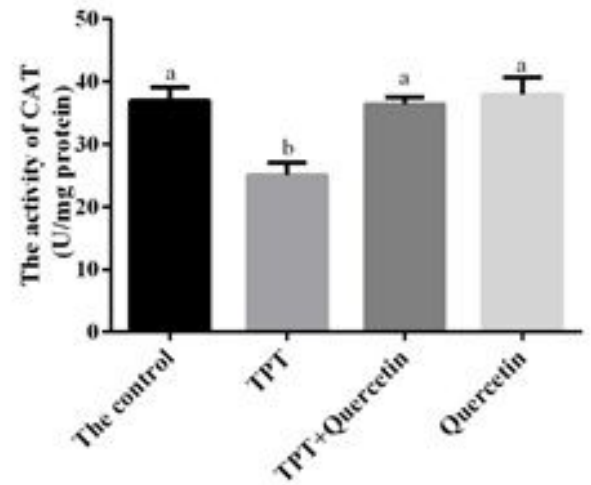

\section{Figure 1}

Effects of TPT and quercetin on hepatic oxidative damage parameters ((A) MDA, (B) NO, (C) GSH, (D) GPX, (E) SOD and (F) CAT) in the liver of zebrafish. Data were expressed as mean \pm SEM and analyzed by One-way ANOVA, followed by turkey's multiple range test $(n=9)$. Different letters denote significant difference $(P<0.05)$.. 
A

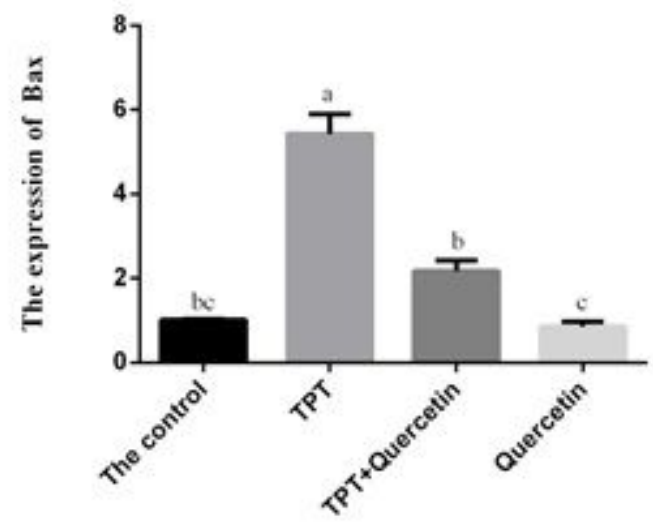

C

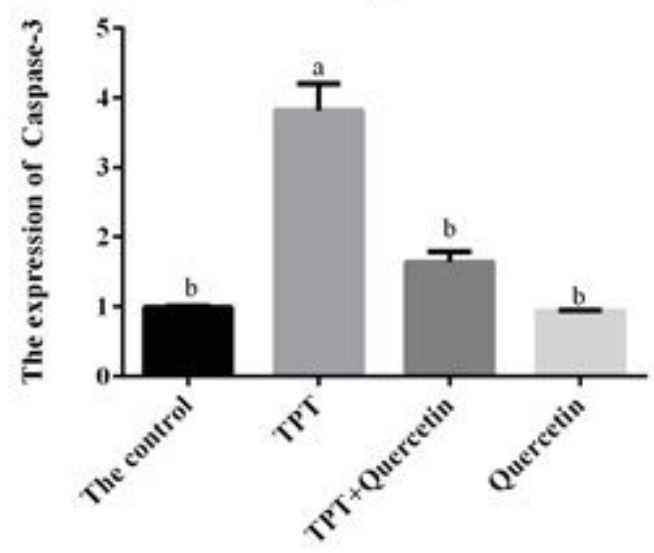

B

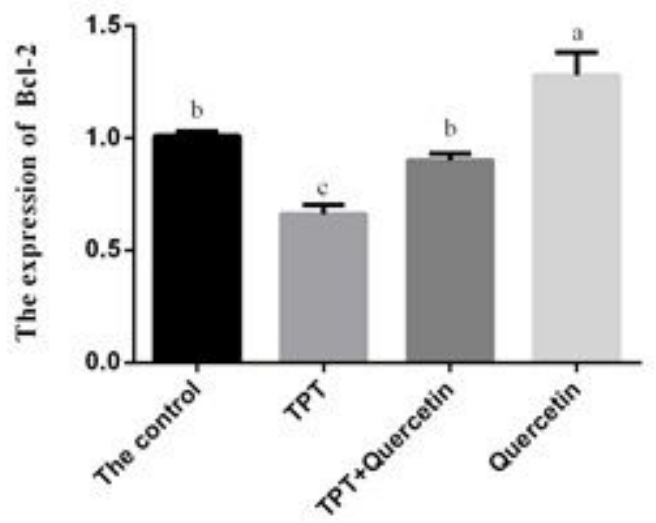

D

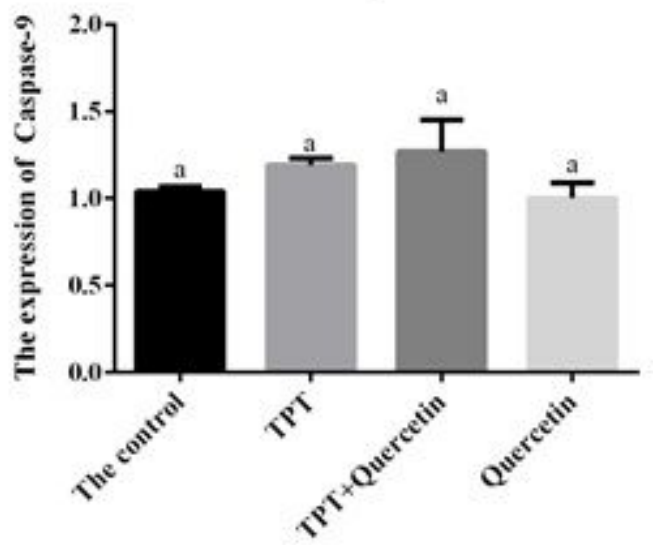

Figure 2

Effects TPT and quercetin on apoptosis-related gene expression ((A) Bcl-2, (B) Bax, (C) caspase3, and (D) caspase9) in the liver of zebrafish. Data were expressed as mean \pm SEM and analyzed by One-way ANOVA, followed by turkey's multiple range test $(n=9)$. Different letters denote significant difference $(P<$ 0.05). 
A

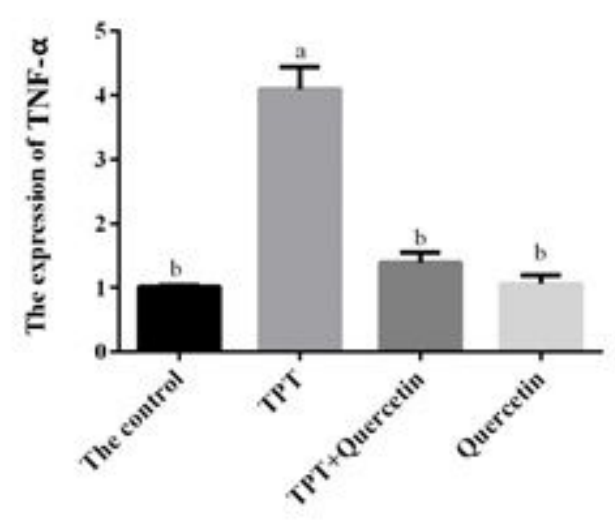

C

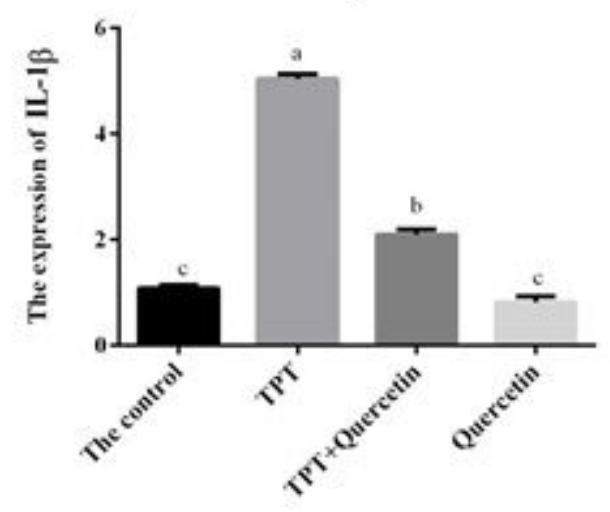

E

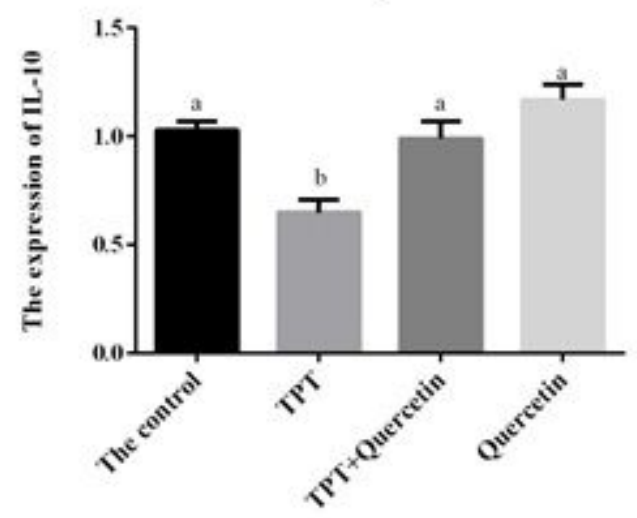

B

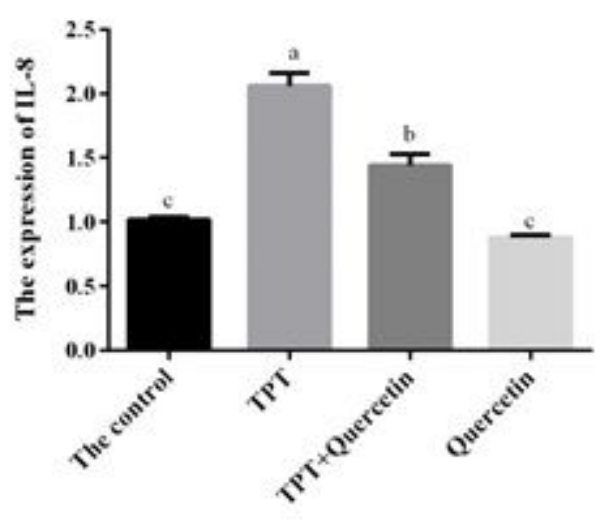

D

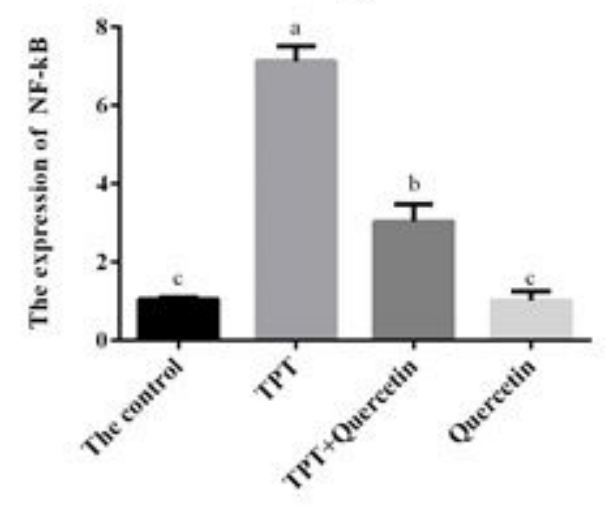

$\mathbf{F}$

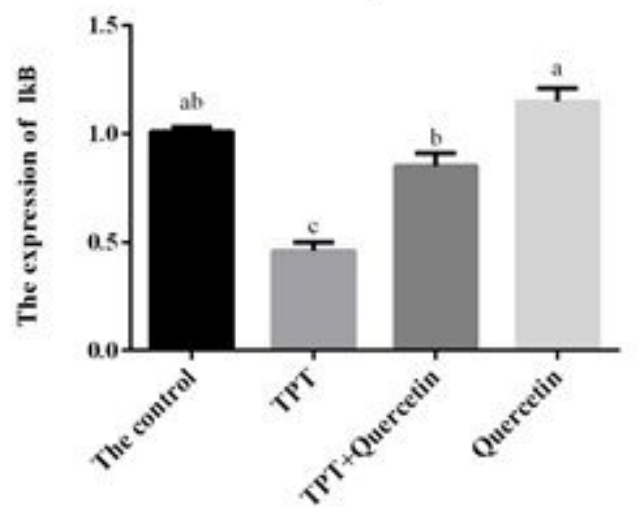

Figure 3

Effects TPT and quercetin on TNF-a, IL-8, IL-1 $\beta$, NF- kBp65, IL-10 and IkB gene expression in the liver of zebrafish. Data were expressed as mean \pm SEM and analyzed by One-way ANOVA, followed by turkey's multiple range test $(n=9)$. Different letters denote significant difference $(P<0.05)$. 